\title{
Exploring the Diversity of Virtues Through the Lens of Moral Imagination: A Qualitative Inquiry into Organizational Virtues in the Turkish Context
}

\author{
Fahri Karakas $^{1} \cdot$ Emine Sarigollu $^{2} \cdot{\text { Selcuk } \text { Uygur }^{3}}^{3}$
}

Received: 2 March 2015/Accepted: 28 March 2016/Published online: 20 April 2016

(c) The Author(s) 2016. This article is published with open access at Springerlink.com

\begin{abstract}
The purpose of this article is to introduce a multidimensional framework based on the concept of moral imagination for analysing and capturing diverse virtues in contemporary Turkish organizations. Based on qualitative interviews with 58 managers in Turkey, this article develops an inventory of Turkish organizational virtues each of which can be associated with a different form of virtuous organizing. The inventory consists of nine forms of moral imagination, which map the multitude of virtues and moral emotions in organizations. Nine emergent forms of moral imagination are based on: integrity, affection, diligence, inspiration, wisdom, trust, gratefulness, justice, and harmony. The findings have made a contribution to the expanding literature on how Islamic organizations develop their business ethics through a repertoire of virtues. An empirical account of the range of virtues in organizational contexts that have emerged as a result of the hybridization of Islamic virtue/aesthetics and neoliberal capitalism in contemporary Turkey is provided. A theoretical contribution is made to business ethics literature through a phenomenology of virtues that provides unique insights on diverse forms of moral imagination in
\end{abstract}

Fahri Karakas

F.Karakas@uea.ac.uk; fahrikarakas@gmail.com

Emine Sarigollu

emine.sarigollu@mcgill.ca

Selcuk Uygur

Selcuk.Uygur@brunel.ac.uk

1 Norwich Business School, University of East Anglia, Norwich NR4 7TJ, UK

2 Desautels Faculty of Management, McGill University, 1001 Sherbrooke Street West, Montreal, QC H3A 1G5, Canada

3 Brunel University London, Uxbridge UB8 3PH, UK contemporary Turkey where Islam and neoliberal capitalism dynamically co-exist.

Keywords Moral imagination · Organizational virtues · Virtuous organizing · Qualitative research · Moral emotions

\section{Introduction}

This study contributes to the expanding literature on how Islamic organizations develop their business ethics through a repertoire of virtues. We develop an empirical account of the range of virtues in organizational contexts that have emerged as a result of the hybridization of Islamic virtue/ aesthetics and neoliberal capitalism in contemporary Turkey. As the global capitalist system and the Anatolian tigers - the newly rising Islamic entrepreneurial firms in Turkey-interpenetrate and transform each other, we are witnessing the unfolding of a new synthesis between Islam and neoliberal capitalism. This paper aims to build a phenomenology of 'virtues' based on the synthesis of Islam and neoliberal capitalism in contemporary Turkey.

The purpose of this article is to introduce a multidimensional framework based on the concept of moral imagination for analysing and capturing diverse forms of virtues in Turkish organizations. Can we gain a more eclectic vision of organizational virtues by attending to, and learning from managers' moral imagination? This paper grapples with multiplicity of virtues in the Turkish cultural context and aims to make sense of this diversity through the concept of moral imagination. Based on qualitative interviews with 58 managers in Turkey, this article develops an inventory of organizational virtues each of which can be associated with a different form of virtuous 
organizing. The inventory consists of nine forms of moral imagination, which map the multitude and diversity of virtues in Turkish organizations. The nine forms of moral imagination are based on integrity, affection, diligence, inspiration, wisdom, trust, gratefulness, justice, and harmony. This paper develops a conceptual framework to explain different understandings of moral imagination through these nine virtue clusters.

\section{Defining Moral Imagination}

There are two streams of research on moral imagination each of which can be associated with a particular type of thinking and a corresponding definition. The first stream is grounded within the business ethics literature; and views moral imagination from a cognitive perspective based on decision-making. Whitaker and Godwin (2013) have defined moral imagination as a unique cognitive process that an individual applies when making a decision. Werhane $(1998,1999,2008)$ has defined moral imagination as the ability to discover and evaluate possibilities not merely determined by that circumstance, limited by its operative mental models, or merely framed by a set of rules. In these accounts, moral imagination is mostly equated with a rational approach based on a framework for decisionmaking. According to Werhane (1998), developing moral imagination involves heightened awareness of contextual moral dilemmas and their mental models, the ability to envision and evaluate new mental models that create new possibilities, and the capability to reframe the dilemma and create new solutions in ways that are novel, economically viable, and morally justifiable. In this stream of work, moral imagination is characterized as an ability that one does (or does not) demonstrate when approaching a situation. Moral imagination is seen at the basis of moral decision-making and positive behaviour in the workplace.

The second stream of research on moral imagination is rooted within the field of social anthropology and it is focused on relating with the self and the other. Building on anthropological work and conceptualization, Moore (2011) has described moral imagination as the unique human ability to imaginatively engage with others, to develop bonds with people over space and time, and to put oneself into the place of the other. Moore characterizes moral imagination as the disruption of the typical ways of thinking and imagining the possibility of connecting to other people in a different way. The exercise of the moral imagination helps us view a human being not simply as a client, customer, or competitor, but rather as a fellow human being to be regarded with respect.

In this paper, we use the definition of Vidaver-Cohen (1997) that moral imagination is the ability to develop fresh interpretations and imagine unconventional alternatives in order to achieve what is more virtuous and desirable. Indeed, moral imagination entails the ability to imagine new possibilities about what is just, good, and virtuous (Moberg and Caldwell 2007) and it helps the individual to think more creatively in relation to what is morally viable (Moberg and Seabright 2000). It involves discovering and constructing moral problems; as well as envisioning creative solutions for these problems (Werhane 2008). Johnson (1993) argues that humans do not make ethical decisions by rationally applying universal laws to concrete situations; but they engage in moral imagination as they reflect on ethical implications of their everyday actions. There has also been recent work across the fields of moral psychology and cognitive/neurobiological sciences that explore the close relationships of emotions, moral reasoning, and moral imagination (Huebner et al. 2009; Langdon and Mackenzie 2012; Tangney et al. 2007). Building on this stream of research, we suggest that moral imagination is closely related to moral emotions and moral judgements. This study aims to explore these relationships through the lens of moral imagination and its diverse forms in the socio-cultural context of Turkey.

Nine different metaphors for the virtuous organization are derived from the respondents' descriptions of their moral imagination during the interviews. They are Organization as a well-oiled system, intimate family, talent fest, art workshop, human brain, closely knit community, playspace, court room, and round table. These nine metaphors correspond to the nine forms of moral imagination; each presenting a specific set of virtues as central to the organization's healthy functioning. Together, these nine metaphors have the potential to advance thinking about organizational virtues beyond a singular vision of virtue ethics, and provide a broader and more inclusive understanding of moral imagination.

This paper will contribute to the theoretical and empirical development of the virtues literature by inquiring the multitude and diversity of moral imagination. We introduce a framework for analysing diverse forms of moral imagination in the context of Turkish organizations. The framework is intended to help fill the gap of holistic theories in the current virtues literature by expanding and systematizing how managers engage in moral imagination as they dream about their ideal organizations.

\section{Virtues in Organizational Literature}

Virtues have recently become a significant topic of examination among organizational researchers who are exploring their role in creating more progressive, compassionate, and humane work environments (Bertland 2009; Cameron et al. 2004; Dyck and Wong 2010; Moore 2013; Provis 2010; Whetstone 2005). As organizations which have long 
been viewed as rational systems are considering making room for emotions, meaning, spirituality, and community (Ashmos and Duchon 2000); researchers are calling for more theories and research on creating virtuous organizations (Manz et al. 2006; Neubert 2011; Whetstone 2003). The Canadian Journal of Administrative Sciences has recently published a special issue titled "Virtues in Organizations: Cultivating Creativity, Collaboration, and Collective Wellbeing" to investigate the positive dynamics of virtuous organizing (Neubert 2011). On the practice side, we have been witnessing a movement toward business organizations with a socially responsive, virtuous, and humanitarian edge (Hollender et al. 2010; Hsieh 2010). Although this body of literature illustrates holistic and multidimensional nature of human virtues in organizational systems, it usually omits cultural specificity. This paper is a step toward filling that gap.

A large set of virtues have been discussed in organizational literature as enablers of organizational effectiveness including integrity (Rozuel and Kakabadse 2010), courage (Harris 1999), fairness and justice (Taylor 2001), service to others (Fairholm 1997; Kriger and Hanson 1999), humility (Kriger and Hanson 1999), and forgiveness (Bright et al. 2006a, b). Although these virtues as well as others are recognized in the literature, it seems that these virtues are addressed without any systematic effort to be comprehensive. On each piece written, some virtues are emphasized while others are neglected. An exception to this pattern is the influential work of Peterson and Seligman (2004) who came up with a classification of 24 virtues and character strengths using a positive psychology approach. However, their work does not focus on virtues in the context of organizations and organizational life; instead it draws from diverse cultures and historical periods to conceptualize and organize character strengths and virtues (Dahlsgaard et al. 2005). This study will build on this body of work, but will inquire the nature of diverse virtues in the context of contemporary Turkish organizations.

The current understanding of virtues and virtuousness in organizations is still 'adolescent' (Sonpar and GoldenBiddle 2008) and not yet been fully developed. Little empirical research focuses on the diverse types of virtues in organizations. Drawing on the emerging discourse of the virtues literature, this paper explores the diverse range of human values and virtues in the context of Turkish organizations. Based on qualitative data collected from 58 managers in Turkey, this study illustrates how virtuous organizing can be manifested in nine different sets of human virtues in organizations. In doing so, we derive a multidimensional typology of virtue clusters in Turkish organizations based on empirical results; contributing to Bacharach's (1989) criterion of clarity and robustness for the construct of virtues in organizations. While a typology does not constitute a theory in itself (Sutton and Staw 1995), it can be considered an initial step towards building theory on virtues in organizations (Bacharach 1989).

\section{Methodology}

Wilson (1998) suggested that qualitative research would be most beneficial for the investigation of complexities and processes, little known innovative ways of organizing, an unstructured and informal linkages in organizations. According to these criteria, qualitative research is a good fit for investigating perspectives on virtuous organizing and organizational virtuousness. Qualitative data for this article come from a sample of 58 managers in a variety of companies (e.g., financial, manufacturing, consulting, and telecommunications) and civil initiatives in Istanbul, Turkey. The aim was to include managers in a wide range of organizations, as well as those with a variety of work contexts, jobs, and positions. Table 1 provides demographic information about the sample.

The respondents were interviewed about their perceptions of virtues and virtuousness as well as their individual views and values about their organizations. The interviews varied between $35 \mathrm{~min}$ to one hour in length and were conducted in Turkish. Questions asked were open-ended in nature and allowed the respondents to reflect on and freely elaborate on their feelings and thoughts about organizational virtues. The aim was to encourage informants to talk freely and openly about what they perceived to be significant. For example, "How would you describe an ideal organization? Reflecting on your values, which virtues are most important? Which virtues are indispensable in your work? Why do you think so? What is your role as a manager to nurture these virtues in your organization?" Further information on the interview protocol, issues probed, memos prepared for data analysis is in the Appendix. All interviews were treated as confidential and all identifying information was removed. They were audio-recorded and transcribed verbatim for analysis.

Table 1 Demographic information

\begin{tabular}{lll}
\hline Demographic information of the sample $(N=41)$ \\
\hline Gender & $60.9 \%$ men & $39.1 \%$ women \\
Education (degree) & $36 \%$ post-graduate & $64 \%$ undergraduate \\
Organization & $78 \%$ business org. & $22 \%$ NGOs \\
Nationality & $92 \%$ Turkish & $8 \%$ other \\
& Mean & Range \\
Age & 32 & $25-48$ \\
Years experience & 6 & $3-14$ \\
\hline
\end{tabular}


A core challenge in this study has been to produce a dataset based on the multiple voices and perspectives. In order to try to find ways of letting participants who are being studied speak for themselves, interview data have been consulted repeatedly and the emergent results and analysis were shared with participants to get their feedback on their representation.

\section{Data Analysis}

For purposes of the study reported here, a grounded theory approach (Glaser and Strauss 1967) was used together with metaphor analysis (Schmitt 2005); with a focus on material specifically related to virtues and virtuousness.

To make sense of the metaphors managers have used to construct analogies, we have used metaphors analysis (Andriessen and Gubbins 2009; Cameron et al. 2009; Cameron and Maslen 2010), with a particular attention on the processes of metaphor categorisation and labelling. We followed Morgan's (1986) approach in teasing out the implications of each metaphor for understanding and managing organizations. By investigating respondents' use of metaphors, we were able to understand their values, attitudes, and conceptualisations, as participants in organizational life (Spicer 2011). Metaphor analysis was used to explore the underlying conceptualizations and imagery that give rise to different organizational metaphors and put them in perspective (Schmitt 2005). Metaphors analysis helped us to reassess the categorization of diverse forms of moral imagination, and to identify how different metaphors relate to each other as well as how these metaphors impact further theorization on organizational virtues. During data analysis, we have tried to discover the diversity of metaphors to arrive at a holistic picture; keeping in mind that preference for a particular metaphor may constrain the ability to see in terms of other plausible metaphors (Morgan 1980).

The interview transcripts were read to extract data on these individuals' personal definitions, descriptions or conceptions of most significant virtues in organizations. An analytic memo was then composed for each case, reproducing the relevant material found (Patton 2002) and summarizing the metaphors and symbols associated with data. Then these 58 analytic memos were reviewed to identify patterns in core virtues described. The authors paid special attention to the diversity and incidence of the recurrent themes in responses regarding virtues. After the transcribed interviews were re-read; first level codes were assigned according to how participants described virtues in organizations. These first level codes were then grouped into different forms of moral imagination. The researchers reviewed all the analytical memos using the method of constant comparison advocated by Glaser and Strauss
(1967), and produced the following building blocks for a tentative framework (Patton 2002): (1) A set of profiles that capture similarities and differences in respondents' descriptions of virtues; (2) A catalogue of the kinds of organizational virtues; (3) A set of metaphors and concept maps that capture the richness and texture of virtuous organizing. The data analysis proceeded in an iterative fashion of analysing qualitative memos, developing narrative accounts, and analysing metaphors. All these data were used to generate an inventory of contemporary organizational virtues in the Turkish Islamic context. The process evolved and unfolded recursively (Patton 2002); and as a result nine distinct forms of moral imagination emerged each of which corresponded with specific metaphors. After several iterations, we reached a point of theoretical saturation where these clusters were clear. Two research assistants, blind to this study's scope, coded all interviews into these nine categories, and the Cohen's kappa across coders was 0.74 .

\section{Results}

The interviews revealed a number of common themes in what virtues these managers were fundamentally looking for in their work. The data suggested that there were implicit theories in the minds of the participants regarding organizational virtues that are most significant or salient for their organizations. For some managers, virtuousness is intrinsically related to building a sense of community and cohesion. For others, it reflects a high level of work ethics and discipline. Yet, for others, virtuousness is linked with creativity and inspiration at work. As a result of the qualitative data analysis, the grouping of the recurrent themes in the analytic memos surfaced nine different forms of moral imagination, which capture the diversity of ethical virtues in Turkish organizations (See Table 2). The following results are meant to be exploratory and these forms of moral imagination represent overarching patterns mapping the multiplicity and diversity of virtues in Turkish organizations.

\section{Integrity-Based Cluster}

Participants having this form for moral imagination have talked about virtues of grace, dignity, and integrity. The key words consistently used by respondents were 'edep' and ' $a d a b$ ', referring to Islamic notions of proper behaviour and etiquette (Sehlikoglu 2013). 'Having created the universe in a perfect order, Allah created humans in the most beautiful form (ashen-i-takvim)' stated a participant, 'Therefore, humans need to keep up to the expectations of their Creator through moral integrity and moral excellence'. 
Table 2 Nine emergent forms of moral imagination

\begin{tabular}{|c|c|c|c|}
\hline $\begin{array}{l}\text { Moral } \\
\text { imagination }\end{array}$ & Process for virtuous organizing & $\begin{array}{l}\text { Metaphor of virtuous } \\
\text { organization }\end{array}$ & Set of virtues \\
\hline Integrity & $\begin{array}{l}\text { Establishing \& routinizing ethical ground rules } \\
\text { to maintain an ideal order }\end{array}$ & Well-oiled system & $\begin{array}{l}\text { Excellence, grace, perfection, honesty, } \\
\text { dignity, integrity }\end{array}$ \\
\hline Affection & $\begin{array}{l}\text { Helping \& serving people, developing rapport \& } \\
\text { reaching hearts }\end{array}$ & Intimate family & $\begin{array}{l}\text { Love, empathy, caring, compassion, } \\
\text { mercy, kindness, gentleness, } \\
\text { helpfulness, generosity }\end{array}$ \\
\hline Diligence & $\begin{array}{l}\text { Positive energy \& constant progress towards } \\
\text { work ethics }\end{array}$ & Talent fest & $\begin{array}{l}\text { Conscientiousness, self-discipline, } \\
\text { steadfastness, ambition, zeal, diligence }\end{array}$ \\
\hline Inspiration & $\begin{array}{l}\text { Creating a new collective identity through a } \\
\text { deeper search for meaning } \& \text { authenticity }\end{array}$ & Art workshop & $\begin{array}{l}\text { Sensitivity, emotional honesty, } \\
\text { authenticity, equanimity }\end{array}$ \\
\hline Wisdom & $\begin{array}{l}\text { Engaging in deep inquiry, continuous learning \& } \\
\text { reflexivity }\end{array}$ & $\begin{array}{l}\text { Learning organization, human } \\
\text { brain }\end{array}$ & Enlightenment, foresight, curiosity \\
\hline Trust & $\begin{array}{l}\text { Knitting a tight network of trust; developing a } \\
\text { collective sense of commitment \& dedication }\end{array}$ & $\begin{array}{l}\text { Closely knit \& well-trusted } \\
\text { community }\end{array}$ & $\begin{array}{l}\text { Loyalty, faithfulness, dependability, } \\
\text { trustworthiness }\end{array}$ \\
\hline Gratefulness & $\begin{array}{l}\text { Process of flow and play where imaginative \& } \\
\text { playful attitudes are rewarded }\end{array}$ & Play-space & $\begin{array}{l}\text { Thanksgiving, gratefulness, openness, } \\
\text { innovativeness, joyfulness, imagination, } \\
\text { novelty, flexibility }\end{array}$ \\
\hline Justice & $\begin{array}{l}\text { Allocating rights \& responsibilities equitably for } \\
\text { everyone }\end{array}$ & Court room & Magnanimity, courage, equity \\
\hline Harmony & $\begin{array}{l}\text { Building dialogue \& developing consensus } \\
\text { among organizational stakeholders }\end{array}$ & Round table & $\begin{array}{l}\text { Patience, respect, universality, } \\
\text { peacefulness, wholeness, tranquillity }\end{array}$ \\
\hline
\end{tabular}

Virtuous organizing was perceived as a process of establishing and routinizing the ethical ground rules to maintain an ideal order. The ideal virtuous organization fits with the metaphor of 'a well-oiled system' where rules of conduct are clear and consistent. In order to reach this virtuous organization, employees and managers need to act with integrity in a disciplined, purposeful, and self-controlled manner. This set of virtues may cause employees to be dissatisfied with the current reality, as they will quickly perceive imperfections and mistakes around them. Four participants mentioned "a constant struggle towards perfection" as they follow the pursuit of excellence. This perfectionism is defined through attention to details, rules, and principles. One of the managers who works in the haute cuisine sector mentioned how his team in the kitchen made sure dishes would taste exactly the same way even if they were cooked a hundred times:

The pursuit of culinary excellence demands a very rigid discipline, constant planning, and consistent routines. We work by seconds, not minutes. I rely on a team of incredibly dedicated people. Each of us here is devoted to the virtue of excellence. We dedicate our lives for the creation of something exciting and enchanting.

As integrity-based moral imagination is focused on the aspiration to make a better world, it is inevitably linked to emotions of despair and moral rage when the desired ideal world is shattered to pieces. In the words of a senior female activist in an NGO for women rights:

As an organization, we are working hard to contribute to the condition of minorities and women in this country. However, women are still beaten and raped in this country; and neither our obsolete laws nor our barbaric mind-sets can protect them. Shame on us.

\section{Affection-Based Cluster}

Participants mentioned the virtues of compassion, generosity, and affection, viewing them connected as a group. The words they have used to describe these virtues were 'muhabbet' (love or affection), 'uhuvvet' (close friendship or fraternity), ' $h u b b$ ' (Love for God and fellow humans), and 'sohbet' (communion or conversation). 18 participants talked about the significance of various emotions-love, compassion, and affection-as core virtues in an organization. These virtues are seen as fundamental shared values in an organization that bond people together. Thus, virtuous organizations are characterized by high-quality emotional relationships that flourish and nourish the social fabric of the human system. The virtuous organization is seen in the light of the metaphor of 'an intimate family'. In the words of a manager working in a private hospital in Istanbul:

I am dreaming of a workplace where everyone shows individual attention and care for one another. Your 
colleagues are empathic and your manager is nurturing as well as encouraging. There is a family atmosphere of intimacy and love. Everyone on the team feels valued and connected. There is high cohesion among the team and the absence of even one member makes a difference. Sports teams can achieve this, why shouldn't we in our organization?

In order to reach these ideals, employees develop emotion-based mutually caring relationships and commitments with one another. Virtues such as compassion and affection enable employees to feel belonging to their organization and perceive it as their community. Several participants mentioned "reaching the hearts of people", "leaving fond memories", and "sharing laughter" as indicators of living in a virtuous organization where they felt at home. Some of the virtuous behaviours mentioned by participants included organizing charity activities, transcending self-interests for the sake of others, donating for a common cause, and helping a disabled employee or a troubled customer by meeting their needs. One manager, working at the intensive care unit of a private hospital in Istanbul, has stated how their team valued care and compassion above any other virtue, as this was the most critical factor in ensuring the well-being of their patients:

We have seen time and again our patients recover much faster with hope. Like a tree growing with water, hope grows with care and compassion. When our patients recover and thank us, this is the biggest gift for us. We feel we are making an impact and we are renewed. This keeps us from burnout due to emotional labour.

Grant and Gino (2010) demonstrated that receiving expressions of gratitude increases prosocial behaviour through enabling individuals to feel socially valued. In other words, kindness and compassion lead to more kindness and compassion, triggering a positive spiral of affection.

\section{Diligence-Based Cluster}

Participants having this form for moral imagination have talked about the virtues of conscientiousness, persistence, zeal, and diligence. Referring to Sufi philosophy, they mentioned four phases of spiritual experiences of engaging in crafts and work, all of which are emotion-based: Ask (being invited to work through love and desire), Sevk (engaging in work through passion and determination), Meşk (setting to work with its flow and rhythms), and Zevk (enjoyment that comes through work). Nine participants have stressed that work in daily life can be seen as a virtuous task. For example, one of them has mentioned how working and 'bread earning' are considered to be very important social and religious values in Turkey. Another participant, perceiving work from a religious perspective, mentioned that Islam oversees human life as a whole, and encompasses daily matters such as work as a form of virtuousness. He stressed how he believed in the necessity of hard work as an end in itself and as a form of prayer. Three respondents mentioned how they loved their job and viewed their work as a path to maturation and growth. According to this perspective, virtuous organizing can be seen as constant progression and striving towards work ethics. Virtuous organizing was depicted in phrases and terms such as 'maintaining vibrancy', 'a collective sense of dynamism and progress', 'positive emotion, energy and momentum', and 'growth and development'. Ethical success is admired as a core virtue; while working hard, being focused, motivating people, achieving goals, focusing on results, and performing well are constantly celebrated. The virtuous organization is seen in the light of the metaphor of 'a talent fest', which functions on the basis of meritocratic rules:

When we make every effort to reach our best selves, we will become an exemplary organization. Such an environment would be very positive, motivating and encouraging. When we give people opportunities to shine and grow, they can excel. That is how I envision this company. We want to be a hotbed of best talent and creativity. In this organization, both individual and team success are recognized and rewarded.

In order to realize such a vision, employees would work with a sense of pride and passion. Jobs would mean more than just work, but they would also represent virtuous and noble ways of life. The workplace would be seen as a natural habitat to thrive, learn, grow, and shine. Four respondents mentioned 'unleashing own passions at work' as an ingredient of ethical success. Some of the virtuous behaviours mentioned by participants included loving own work, working hard, setting and achieving challenging objectives, and persisting in the face of hardships. Participants described an Islamic ethics of hard work, where Islam was seen as compatible with entrepreneurship, investment, and global capitalism. These findings can be interpreted within the wider socio-cultural context in Turkey where the current neoliberal policies support both the Islamization of capitalism and the construction of entrepreneurial Islam. As the global capitalist system and the Anatolian tigers - the newly rising Islamic entrepreneurial firms in Turkey-interpenetrate and transform each other, we are witnessing the unfolding of a new synthesis between Islam and neoliberal capitalism. This synthesis is visible in the outcomes such as the rise of the Islamist bourgeoisie, the rising purchasing power of Turkish 
religious-conservative consumer segments, the growth of 'green capital', the emergence of luxurious forms of consumption, and the flourishing of new 'alternative' industries ranging from Muslim haute couture to veiled hotels.

\section{Inspiration-Based Cluster}

Participants having this form for moral imagination have talked about the virtues of self-awareness, creativity, sensitivity, emotional honesty, authenticity, and equanimity. They mentioned the words of cemal (beauty), sanat (art), letafet (fineness), and mana (deeper meaning). One participant explained how the creator could be seen as the ultimate artist (Sani'i) as worthy of all praise and how the beauty of all creations uplifts human hearts. Another respondent mentioned the deeper side of creativity involved 're-creating the self through artwork, stories, reflection, questioning, and continuous alchemical refinement'.

Art, beauty, and aesthetics are seen as inevitable elements of an ideal virtuous organization. Five managers mentioned how the realm of aesthetics can inspire a sense of ethics and how the search for beauty can also contribute to the search for good. Involvement in arts such as reading poetry, playing or listening to music, viewing a performance at the theatre, or contemplating a classic painting can indeed help an individual to search for the better and nobler self. Therefore, virtuous organizing is perceived as a process of creating a new collective identity through a deeper search for meaning and authenticity. The virtuous organization is seen through the light of the metaphor of 'art workshop' where self-awareness and reflection are deeply valued:

An ideal organization would be somewhere I can fully express my deep feelings and follow my inner voice. Our work should be personally meaningful and spiritual. We should strive for beauty and creativity. We should inspire each other. We should discover and unleash the true gifts of one another. We can only do these through the arts. Arts help us unleash our best selves.

This approach represents a mix of interpretive, hermeneutic, symbolic, and postmodern approaches to organizing. In this approach, virtues can be seen as social constructions and shared meanings that make an organization a distinct and unique entity. Towards this end, some of the virtuous behaviours mentioned by participants are searching for organizational identity, searching for a deep sense of meaning at work, expressing own feelings, and narrating powerful stories. One respondent who is working as a manager and consultant in the creative sector in Cihangir, Istanbul, comments on the importance of deeper meaning and inspiration as follows:
The human quest for significance manifests itself in the desire to leave a legacy of distinction. We have reached awe-inspiring peaks in science, arts, technology, and progress. We have travelled the space and built skyscrapers. Yet we are yearning for more-something is lacking in our inner worlds. We have somehow become poorer in our humanity. In every corner of this city you will see shopping centres (AVM) and consumption. Yet you will see much fewer spaces for reflection and inspiration. We have not only lost Emek Cinema or Inci Patisserie; we have seen how the rich artistic tapestry of Sulukule has been transformed into a monstrous desert of cement. Are we losing virtues? Yes. We have forgotten the simple art of living together. We have forgotten the meaning of living gracefully.

\section{Wisdom-Based Cluster}

Participants mentioned the following virtues and viewed them as connected with each other: 'basiret' (insight, discernment), 'firaset' (clarity and speed of perceptive mind), enlightenment, and willingness to learn. Three respondents have mentioned the importance of 'tefekkür' in the workplace. This word, tefekkür, means profound thinking and discovering in the name of God. Exploration, discovery, and thinking are regarded as sacred and spiritual activities in this Islamic discourse. "The greatest book to be read is the human being. The universe is within the human, the human is within the Universe", one respondent said. In this perspective, the virtuous organization is seen as a place of learning and wisdom:

I dream of a company where employees are encouraged to allocate time to continuously learn, discover new things, create knowledge, and go deeper in their expertise. Such a company would be reflexive and wise in its strategies, because it invests in the quality and knowledge of its people.

This perspective represents a mix of cognitive, analytical, and reflective approaches to organizing. In this approach, virtuous organizing would be made possible by deep inquiry, continuous learning, and reflexivity. Forms of moral imagination mentioned by participants included trying to discover and make sense of the world, creating and sharing knowledge, reading and understanding, and being curious. Participants have talked about these virtues through locating those virtues in relation to societal trends, cultural expectations, and organizational necessities. Moral imagination is inevitably linked to imagining new possibilities about creating a virtuous world and organization. Therefore, moral imagination provides idealist narratives 
on employee rights, diversity at work, and business ethics, propagating discourses on achieving justice, well-being, and progress at work.

\section{Trust-Based Cluster}

Participants having this form for moral imagination have talked about the virtues of loyalty, faithfulness, dedication, and trustworthiness. The recurrent word used to express these virtues was 'sadakat', which denoted loyalty to God, to the Messenger, to Islamic values and teachings, and to the community. Ten participants mentioned the significance of standing together with fellows and supporting them in hard times. Six managers mentioned that loyalty and trust are indispensable values for the survival and sustainability of the system. They said systems live because of the close support and loyalty of their believers and followers. Virtuous organizing was depicted in phrases and terms such as 'knitting a tight network of trust and loyalty', 'building a community of idealist people', and 'developing a collective sense of commitment and dedication'. In this perspective, the virtuous organization was conceptualized as the metaphor of 'a closely knit and a well-trusted community':

An ideal place to work is where you can fully trust your colleagues. You can share all your secrets and you know that nobody will betray your trust. You can depend on them during hard times. You feel part of something bigger and belong to a community.

In order to realize such a vision, loyalty and trust are key ingredients for organizing. Virtuous organizing is made possible by a shared sense of belonging, community, and responsibility. Some of the virtuous behaviours mentioned by participants are carrying out duties as a loyal member, ensuring a close atmosphere of trust, taking precautions in difficult times, as well as protecting the fundamental values of the organization.

\section{Gratefulness-Based Cluster}

Participants having this form for moral imagination have mentioned the virtues of gratefulness, novelty, and flexibility. The specific word to describe gratefulness was 'şükür', which involves expressing gratitude, thanks and appreciation. Participants frequently used the phrase ' $\mathrm{Al}$ hamdulillah' which means 'All thanks and praise belongs to Allah'. In the words of a respondent: 'Having a sense of gratitude is a great blessing for all of us as it embodies a sense of happiness, relieving us of the many pressures and anxieties'. 12 managers mentioned hope and optimism as essential ingredients of positive change in human systems. The key to hope is appreciating and being thankful for the good things in life. Some managers stated that they performed most energetically, creatively, and enthusiastically when they appreciated the people and the world around them. 'If we are to lead positive change, we need to discover and appreciate our strengths as a team. Then, we can build on them and get the momentum that we need', one manager stated. 'The path to building a virtuous organization starts with a shared vision and a dream', another mentioned. Therefore, virtuous organizing is perceived as a process of flow and play where imaginative and playful attitudes are the norm. Positive emotions, energy, fun, and joy are essential elements here. The virtuous organization is therefore seen as a play-space where novelty, enthusiasm, and positive thinking are celebrated. In the words of a manager working in telecommunications sector:

We believe we can contribute to a better world if we can design a work environment and an organizational culture like Google. Work itself is designed like a game. It is fun. Playful, creative and enthusiastic attitudes are rewarded. Many ideas are generated in brainstorming sessions. Energetic and passionate people create exciting things. Everyone is inspired and happy to participate in the process of discovery and exploration.

This perspective represents a mix of dynamic, visionary, and futuristic approaches to organizing. In this perspective, virtues can be viewed as fluid, diverse, and emergent elements of innovative organizing for positive change. Towards this end, some of the virtuous behaviours mentioned by participants are inspiring people to create novel ideas, appreciating the good aspects of life, articulating a vision for the betterment of the world around them, instilling hope, and encouraging positive thinking. A manager working in one of the leading radio stations in Turkey has suggested gratefulness as a core virtue in their programming:

We help our listeners to appreciate and enjoy fun aspects of life. We try to evoke happiness and gratefulness-simply reminding our audience that there are colours, sounds, and landscapes in life that are worth celebrating and being grateful for. We find reasons to celebrate and causes to feel gratitude. We design fun interactions and urban jokes; organizing people for random acts of kindness and craziness. We organize flash mobs and interactive skits in city centres. For example, we organized 200 listeners to participate in a midnight barbecue party along with collective karaoke singing in an Anatolian town. Our fans are pretty self-organized, adventure-seeking, and spontaneous. We operate like a circus. Our job is to create magic. In the end, it is all about sparking 
novelty and evoking a sense of playful adventure; so that we all feel the magic.

\section{Justice-Based Cluster}

Participants having this form for moral imagination have talked about the virtues of courage, justice, and equity. They have mentioned the concepts of 'adalet' (justice) and ' $h a k$ ' (equity), principles which need to be implemented in organizations in accordance with God's name of 'the Just' (al'-Adl). In the words of a respondent, 'Managers need to set matters straight in a fair, impartial and equitable manner. I think there is a delicate balance here and justice does not clash with mercy or compassion. You can still set the record straight without harshly punishing wrong-doers'. Six managers mentioned justice and courage as the most significant virtues that maintain and protect other virtues in human systems. These managers cared most about social justice, impact, and responsibility. 'I am here to protect the rights of my team members and see to it nothing hinders their progress and development', one said. 'If justice is not there, you cannot protect the dignity of people', another stated. Therefore, virtuous organizing is perceived as a process of allocating rights and responsibilities equitably for everyone. The virtuous organization is therefore seen as a courtroom where justice prevails. In the words of a senior manager working in international trade:

As Aristotle has said, all virtue is summed up in dealing justly. At times like these when opportunism and short term profits seem to be everything, we need to find the courage to believe in justice and dignity for all people. Using what we have here, we need to make a contribution to the lives of less fortunate.

Towards this end, some of the virtuous behaviours mentioned by participants included taking initiative for common good, managing people with justice and fairness, leading people to noble causes, protecting the rights of the minorities and the weak, and preventing any form of injustice. A respondent who was working as a manager in a human rights organization summed up the significance of justice as the most critical virtue in human systems:

We need significant reforms in every institution in this country including judiciary, legislative, and executive institutions. As a non-governmental organization, we strive to protect the rights of the weak. Unless we address justice and human rights issues in Turkish institutions, sustainable progress will be a dream than a reality. In order to ensure justice, we have to empathetically listen to minorities; turning their silences to free voices.

\section{Harmony-Based Cluster}

Participants having this form for moral imagination have talked about the virtues of patience, tranquillity, peace, balance, and wholeness. These virtues have been emphasized the most by the participants (21 managers). Several managers mentioned cooperation and harmony as the keys to a respectful and well-functioning community. Some managers talked about the importance of 'istisare' (this word, meaning consultation, refers to the Islamic institution of collective advisory meetings) in organizational life. "Just being patient and listening to everyone's opinions respectfully makes a huge difference. We have istişare because we know that we will be able to reach much more balanced and holistic decisions in a circle. If we form a cooperative circle, every member will contribute to the group through one's own unique gifts and views", one manager said. Therefore, virtuous organizing is perceived as a process of building dialogue and developing consensus among organizational stakeholders. The virtuous organization is seen as a round table where diverse views are reconciled and resolved in harmony:

An ideal organization performs like an orchestra.

There is a sense of flow and common consciousness.

Everyone is playing a special instrument according to his or her own unique talents and gifts. It is not easy to realize such a vision in the messiness of everyday life; as there are inevitable clashes and power games. There are bullies and vampires everywhere-they get their power from domination. You have to have mechanisms to prevent bullying and to protect the weak.

Some of the virtuous behaviours mentioned by participants included valuing diversity, connecting with everyone, being sensitive about individual differences, trying to turn differences into synergy, mediating and resolving conflicts peacefully, seeking out consensus in collective decision-making processes, giving everyone a voice in meetings, and enhancing dialogue with all stakeholders.

\section{Discussion}

Moral imagination is an indispensable element of organizational life and a universal human need; yet it remains elusive and theoretically underdeveloped. The paper has aimed to develop a generative understanding of the concept, which is entangled with the most salient virtues of individuals. In doing so, it has uncovered the creative capacity of individuals in visioning more virtuous human systems. 
As the global capitalist system and the Anatolian tigers - the newly rising Islamic entrepreneurial firms in Turkey-interpenetrate and transform each other, we are witnessing the unfolding of a new synthesis between Islam and neoliberal capitalism. The findings have made a contribution to the expanding literature on how Islamic organizations develop their business ethics through a repertoire of virtues. An empirical account of the range of virtues in organizational contexts that have emerged as a result of the hybridization of Islamic virtue/aesthetics and neoliberal capitalism in contemporary Turkey was provided. The paper has built a phenomenology of 'virtues' based on the synthesis of Islam and neoliberal capitalism in contemporary Turkey.

This paper speaks to the literatures on human virtues, business ethics, moral emotions, and spirituality at work. The research contributes to the literature through underlining the fluidity, multiplicity, and diversity of human virtues and moral emotions in organizations. Through the lens of moral imagination, we call for a more dynamic, holistic, and fluid way of understanding virtues and moral emotions in organizations. By highlighting the importance of moral imagination woven into manager's personal worldviews, we point out how managers construct new imagined possibilities about a virtuous organization through the nine metaphors they used. We also emphasize a future agenda of further research that is sensitive to the complexities of diverse and fluid understandings of virtues and moral emotions in human systems.

Based on qualitative interviews with 58 managers in Turkey, this article has developed an inventory of Turkish Islamic organizational virtues. Specifically, this study introduced nine forms of moral imagination that map the multitude and diversity of virtues in organizations based on Integrity, affection, diligence, inspiration, wisdom, trust, gratefulness, justice, and harmony. In parallel with these forms of moral imagination, nine metaphors were introduced to describe the ideal virtuous organization: Welloiled system, intimate family, talent fest, art workshop, human brain, closely knit community, play-space, court room, and round table. The results also suggested the possibility that certain sets of virtues being more appropriate for certain sectors and organizational contexts. In particular, data illustrated that nine virtue clusters were associated with haute cuisine, health, management consulting, creative arts, publishing, auditing, entertainment, human rights, and non-governmental organizations or sectors, respectively.

This paper proposed a preliminary framework for analysing and capturing diverse organizational virtues by introducing nine forms of moral imagination which offer a basis for a multidimensional theory of organizational virtues. Open-ended narratives revealed that most participants perceived virtues of an organization and the virtues of individuals within an organizational context as inseparable. Hence in an attempt not to artificially restrain the participants' true views and perceptions during the interviews and to preserve the integrity of the data later during the analysis stage, this study did not distinguish between the two levels of virtues intentionally. Instead this study proposes the emerging themes as a bridging framework between the virtues of organizations and the virtues of individuals within an organizational context. Using this framework, future research can explore and elaborate on cross-level effects and develop them into a multilevel model. By acknowledging that there is a meaningful array of forms of experience, this framework celebrates and welcomes multitude of organizational virtues, resulting in different metaphors and visions of virtuous organizing.

This research has a number of contributions as well as theoretical and practical implications for managers and organizations interested in organizational change management. First, this study contributes to organizational virtues literature in identifying the different meanings and expressions of virtues at work in the context of Turkey. The data suggested there was clearly a diverse set of ideas about what moral imagination meant for Turkish managers. The findings in this paper highlight the value of multiple perspectives and interpretations regarding moral imagination and corresponding visions of organizational change. The qualitative data indicate that there are many different paths and processes for virtuous organizing. The emergent framework can be used, further developed and tested to analyse and validate these diverse and multifaceted forms of virtues in various organizations.

Second, the rich empirical data in this study brought to light the relationships among organizational virtues, forms of moral imagination, and the wider societal context. The findings have revealed that the virtues are not only shaped by the local and cultural context; but they can also potentially shape organizational cultures, leadership styles, and organizational practices in this local context. The findings have also underlined the explanatory value of moral imagination in the light of Turkish cultural context and business practices. In particular, moral imagination was found to be pluralistic and shifting based on visions and perspectives of managers. Accordingly, particular forms of moral imagination were associated with particular visions of leadership and organizational change. Organizational change and development practitioners might benefit from learning about and analysing diverse forms of moral imagination and how these forms may be used in leading organizational and social change efforts. Through articulating a vision of organizational change based on a particular form of moral imagination, they can pave the way for organizational change. Thus, forms of moral 
imagination might be used for constructing an appropriate vocabulary and developing relevant methodologies towards achieving desired change.

Finally, this paper has also suggested that organizational virtues are informed by multiple powerful metaphors. Organizational virtues may therefore be better understood if we understand and delineate a multitude of the metaphors on which organizational members' thinking is based. These metaphors may enable us to examine virtues through contrasting lenses, triangulate the different views, and hopefully arrive at a synthesis which recognizes the validity of each viewpoint and its integration with others. Visualizing the virtuous organization as a well-oiled machine empowers us to engage with a mental image which helps us to appreciate its functioning in terms of its strengths and weaknesses. When an organization is described as a well-oiled machine, we perceive it as efficient and orderly; but also as inflexible. People who allow virtue metaphors to become stereotypes may limit themselves in their conceptual repertoire. The use of multiple metaphors will enable managers a well-rounded and balanced perspective.

In summary, the results of this study suggest that the field of organizational virtues can be enriched by nine diverse metaphors and forms of moral imagination. Managers in the organizational system may act like blind men attempting to understand what the elephant looks like by feeling its different parts. Each manager experiences an important and worthy part of the whole picture, but each may become preoccupied with that specific form of moral imagination. As long as managers stay within own comfort zones, they will have only a one-eyed view of the complex, multifaceted nature of organizational virtues. Alternative metaphors may provide fresh lenses enabling them to see more of fascinating complexity or organizational life. For example, harmony, trust, and affection-based clusters might be united to increase interpersonal sensitivity in the organizational system, whereas integrity- and justice-based clusters might be united to increase equity and fair play.

Organizations should think more broadly about the different kinds of contributions which managers can make, and to develop multiple paths to nurture values and virtues in organizations. Using this research, organizations and managers can develop a more profound understanding about the meanings individuals attach to virtues in human systems. They can discover the multiplicity of organizational virtues, speak the language of these virtues, and expand their dictionary on virtues to envision and lead organizational change. They can also design appropriate organizational structures and programs that support particular forms of moral imagination at work. A scale measuring each dimension of virtuousness can be developed for organizations and managers interested in discovering which virtues are salient and dominant versus which virtues are largely absent.

This exploratory study has some limitations that need to be addressed in future research. Without collection of further empirical data and replication of the study in other cultural contexts, it is not clear to what extent the results may be generalizable to different cultural contexts and different samples. From a theoretical perspective, it is plausible that the concept of moral imagination and its various forms can be at least partially useful and applicable in diverse cultural contexts. Nevertheless, the data clearly demonstrate that the emergent categories are the products of contemporary Turkish Muslim context. All the virtues mentioned have their roots in Sufi philosophy and the local socio-cultural context. Accordingly, our findings offer unique insights and implications on organizational virtues in a secular state and in a Muslim country context.

The sample was not probability sample, as judgmental sampling was used. Participants in this study were relatively young, highly educated, and less experienced managers in Turkey. The fact that respondents were young managers may have caused a bias in findings, as this group was idealistic in their conceptions of virtuous organizations, resulting in an almost utopian picture of virtuous organizing. We expect that we would get a more pragmatic and comprehensive picture of virtuousness in organizations through incorporating more experienced and tenured managers in the sample. More senior managers would be able to better reflect on why we do not see the identified set of virtues in actual practice. Therefore, this research should be replicated with diverse samples in different cultural contexts.

It is important to note that these nine forms of moral imagination do not co-exist happily with little discomfort or cross-examination. They may collide and clash with one another. More than half of the respondents stressed the difficulties of finding the right anchor or frame of reference for their ethical decision-making. A recurrent theme that underlies all forms of moral imagination is constant questioning of the self. 18 managers mentioned "nefis muhasebesi" (the Sufi practice of relentlessly questioning the self) as the basis to any moral action. This harsh questioning often involves moral anxiety, doubt, and conflict, as expressed in the words of a manager as follows: "The moment that you feel you are competent and morally superior, you are in danger. You have swallowed the poison of false pride and arrogance. You have to keep questioning yourself and consulting trusted friends and coworkers. These friends ('hayırhah') should be trustworthy and they should have the credit to warn and criticize you harshly". When managers act based on a wrong frame of reference, then these friends warn these managers. Often, the managers experience guilt and regret in these 
cases, which can be channelled towards making positive changes. Managers then revise their decisions, and take morally relevant actions, i.e., act in accordance with the correct form of moral imagination. Our findings support the conclusion of Huebner et al. (2009), who suggest that emotions often follow moral judgments and serve a primary role in motivating morally relevant actions.

\section{Conclusion}

Moral imaginations do not emerge in a vacuum. Moral imaginations, the participants have talked about are shaped within the context of wider socio-cultural provenance, and they are inevitably linked to moral emotions such as moral rage, hope, and hopelessness. Moral imaginations are also inspired by participants' connections with their role models, managers, and colleagues, as they help them explore their virtues through locating those virtues in relation to societal trends, cultural expectations, and organizational necessities. Moral imaginations include many elements of a nexus that creates affective dispositions and new forms of self-making, institution making and world making. Another contextual element of the nexus inspiring participants to imagine new possibilities about creating a virtuous world and organization is the pervasive influence of family and friends, along with their worldviews and values on what constitutes a virtuous person. Moral imagination-as social imaginary shared among employees and stakeholdersprovides desirable and idealist narratives on employee rights, diversity at work, corporate social responsibility, and business ethics, propagating discourses on achieving 'ideal' conditions of justice, well-being, and progress. Moral imaginations of participants are situated and contextualized within the nexus of these interactions, discourses, and influences.

This paper has shown how Turkish managers engage in moral imagination to anchor their everyday actions in the virtues that matter most to them. Moral imagination evokes managers to imagine new possibilities about themselves, their employees, and other stakeholders; triggering them to envision new ways of virtuous organizing. Moral imagination embodies re-imagining the self in relation to other (i.e., stakeholders, employees, community). From an anthropological perspective, imagining an ideal organization signifies a resetting of horizons and the possible start of something meaningful and worthwhile. The passion and commitment expressed by the respondents are linked to profound feelings of hope and aspiration: the desire to make the organization - and the country-a better place. In this respect, moral imagination is linked not only to personal hopes and aspirations; but also to the commitment to respond to the wider issues of injustice in society. It embodies the human capacity for social change and innovation; as well as the moral rage to resist injustice. It underlies human virtues to achieve a better self, a better organization, and a better society. It is woven into the fabric of daily life and it is the fuel of creativity and social innovation in Turkish organizations. The paper has underlined the significance of moral imagination in designing, envisioning, and initiating such spaces of possibility and change.

\section{Compliance with Ethical Standards}

Conflict of interest The authors declare that there is no conflict of interest.

Open Access This article is distributed under the terms of the Creative Commons Attribution 4.0 International License (http://crea tivecommons.org/licenses/by/4.0/), which permits unrestricted use, distribution, and reproduction in any medium, provided you give appropriate credit to the original author(s) and the source, provide a link to the Creative Commons license, and indicate if changes were made.

\section{Appendix: Interview Themes and Issues Probed in Memos}

(1) Analytical Memo on Virtues in Organizations:

Basics about the organization: size, employees, sector, organizational context

Accounts and perceptions of most significant virtues

Salience/significance of particular virtues in the organization

Organizational culture and how it is related to virtues

Perspectives on virtuous management and organizing Perspectives on ideal virtuous organization

(2) Reflective Memo on Virtues in Organizations:

Metaphors, symbols, and language used to describe organizational virtues

Metaphors and language used; subtexts, emotional tone

Emergent frameworks

Faces/dimensions/paradigms of organizational virtues

\section{Preliminary Interview Protocol}

Interviewee general information 
- Age, sex, demographics, job and position

- Years and experiences in the organization, career trajectory

\section{Perceptions of organizational virtues}

- Probe into personal meanings of virtuousness

- Probe into particular virtues: How they perceive specific virtues at work, which virtues they see as most significant/salient

- Probe into participants' core virtues, and how these virtues can be nurtured in their organization

- Probe into what participants' ideal virtuous organization looks like

\section{References}

Andriessen, D., \& Gubbins, C. (2009). Metaphor analysis as an approach for exploring theoretical concepts: The case of social capital. Organization Studies, 30(8), 845-863.

Ashmos, D. P., \& Duchon, D. (2000). Spirituality at work: A conceptualization and measure. Journal of Management Inquiry, 9(2), 134-145.

Bacharach, S. B. (1989). Organizational theories: Some criteria for evaluation. Academy of Management Review, 14(4), 496-515.

Bertland, A. (2009). Virtue ethics in business and the capabilities approach. Journal of Business Ethics, 84(1), 25-32.

Bright, D. S., Cameron, K. S., \& Caza, A. (2006a). The amplifying and buffering effects of virtuousness in downsized organizations. Journal of Business Ethics, 64, 249-269.

Bright, D. S., Fry, R. E., \& Cooperrider, D. L. (2006b). Forgiveness from the perspectives of three response modes: Begrudgement, pragmatism, and transcendence. Journal of Management, Spirituality \& Religion, 3(1-2), 78-103.

Cameron, K. S., Bright, D., \& Caza, A. (2004). Exploring the relationships between organizational virtuousness and performance. American Behavioral Scientist, 47(6), 766-790.

Cameron, L., \& Maslen, R. (2010). Metaphor analysis: Research practice in applied linguistics, social sciences and the humanities. London: Equinox.

Cameron, L., Maslen, R., Todd, Z., Maule, J., Stratton, P., \& Stanley, N. (2009). The discourse dynamics approach to metaphor and metaphor-led discourse analysis. Metaphor and Symbol, 24(2), 63-89.

Dahlsgaard, K., Peterson, C., \& Seligman, M. E. P. (2005). Shared virtue: The convergence of valued human strengths across culture and history. Review of General Psychology, 9(3), 203-213.

Dyck, B., \& Wong, K. (2010). Corporate spiritual disciplines and the quest for organizational virtue. Journal of Management, Spirituality and Religion, 7(1), 7-29.

Fairholm, G. W. (1997). Capturing the heart of leadership: Spirituality and community in the new American workplace. Westport, CT: Praeger Publishers.

Glaser, B., \& Strauss, A. (1967). The discovery of grounded theory. Chicago: Aldine.

Grant, A. M., \& Gino, F. (2010). A little thanks goes a long way: Explaining why gratitude expressions motivate prosocial behavior. Journal of Personality and Social Psychology, 98(6), 946-955.
Harris, H. (1999). Courage as a management virtue. Business \& Professional Ethics Journal, 18(3/4), 27-46.

Hollender, J., Breen, B., \& Senge, P. (2010). The responsibility revolution: How the next generation of businesses will win. San Francisco: Jossey-Bass.

Hsieh, T. (2010). Delivering happiness: A path to profits, passion, and purpose. New York: Grand Central Publishing.

Huebner, B., Dwyer, S., \& Hauser, M. (2009). The role of emotion in moral psychology. Trends in Cognitive Sciences, 13(1), 1-6.

Johnson, M. (1993). Moral imagination: Implications of cognitive science for ethics. Chicago: University of Chicago Press.

Kriger, M., \& Hanson, B. (1999). A value-based paradigm for creating truly healthy organizations. Journal of Organizational Change Management, 12(4), 302-317.

Langdon, R., \& Mackenzie, C. (2012). Emotions, imagination, and moral reasoning. New York: Psychology Press.

Manz, C. C., Cameron, K. S., Manz, K. P., \& Marx, R. D. (2006). Values and virtues in organizations: An introduction to the special issue. Journal of Management, Spirituality, and Religion, $3(1-2), 1-12$.

Moberg, D., \& Caldwell, D. F. (2007). An exploratory investigation of the effect of ethical culture in activating moral imagination. Journal of Business Ethics, 73(2), 193-204.

Moberg, D. J., \& Seabright, M. A. (2000). The development of moral imagination. Business Ethics Quarterly, 10(4), 845-884.

Moore, H. (2011). Still life: Hopes, desires and satisfactions. Cambridge: Polity Press.

Moore, G. (2013). Re-imagining the morality of management: A modern virtue ethics approach. Dordrecht: In The Heart of the Good Institution, Springer.

Morgan, G. (1980). Paradigms, metaphors, and puzzle solving in organization theory. Administrative Science Quarterly, 25, $605-622$.

Morgan, G. (1986). Images of organizations. Beverly Hills, CA: Sage.

Neubert, M. J. (2011). Introduction: The value of virtue to management and organizational theory and practice. Canadian Journal of Administrative Sciences, 28(3), 227-230.

Patton, M. Q. (2002). Qualitative research and evaluation methods. Thousand Oaks, CA: Sage Publications.

Peterson, C., \& Seligman, M. E. (2004). Character strengths and virtues: A handbook and classification. Oxford: Oxford University Press.

Provis, C. (2010). Virtuous decision making for business ethics. Journal of Business Ethics, 91(2), 3-16.

Rozuel, C., \& Kakabadse, N. (2010). Ethics, spirituality and self: managerial perspective and leadership implications. Business Ethics: A European Review, 19(4), 423-436.

Schmitt, R. (2005). Systematic metaphor analysis as a method of qualitative research. The Qualitative Report, 10(2), 358-394.

Sehlikoglu, S. (2013). Takım Elbiseli Müslümanlar: Edep, Kulluk ve Dönüşüm. Zaman, 28 September, 2013.

Sonpar, K., \& Golden-Biddle, K. (2008). Using content analysis to elaborate adolescent theories of organization. Organizational Research Methods, 11(4), 795-814.

Spicer, A. (2011). Metaphors we lead by: Understanding leadership in the real world. London: Taylor \& Francis.

Sutton, R. I., \& Staw, B. M. (1995). What theory is not. Administrative Science Quarterly, 40, 371-384.

Tangney, J. P., Stuewig, J., \& Mashek, D. J. (2007). Moral emotions and moral behavior. Annual Review of Psychology, 58, 345.

Taylor, M. S. (2001). Reflections on fairness: Continuing the progression of justice research and practice. Journal of Vocational Behavior, 58(2), 243-253.

Vidaver-Cohen, D. (1997). Moral imagination in organizational problem-solving: An institutional perspective. Business Ethics Quarterly, 7, 1-26. 
Werhane, P. H. (1998). Moral imagination and the search for ethical decision making in management. Business Ethics Quarterly, Ruffin Series, 1, 75-98.

Werhane, P. H. (1999). Moral imagination and management decisionmaking. Oxford: Oxford University Press.

Werhane, P. H. (2008). Mental models, moral imagination and system thinking in the age of globalization. Journal of Business Ethics, $78(3), 463-474$.

Whetstone, J. T. (2003). The language of managerial excellence: Virtues as understood and applied. Journal of Business Ethics, 44(4), 343-357.
Whetstone, J. T. (2005). A framework for organizational virtue: The interrelationship of mission, culture and leadership. Business Ethics: A European Review, 14(4), 367-378.

Whitaker, B. G., \& Godwin, L. N. (2013). The antecedents of moral imagination in the workplace: A social cognitive theory perspective. Journal of Business Ethics, 114(1), 61-73.

Wilson, V. A. (1998). Qualitative research: An introduction. Purposes, methodology, criteria for judgment, and a rationale for mixed methodology. Report. 